\section{JURNAL EKONOMI EFEKTIF}

ISSN : $2622-8882$, E-ISSN : 2622-9935

Jurnal Ekonomi Efektif, Vol. 3, No. 2, Januari 2021 @Prodi Manajemen Fakultas Ekonomi Universitas Pamulang

\title{
PENGARUH PENEMPATAN KERJA TERHADAP KINERJA KARYAWAN PADA PT. SATRIA PUTRA JAYA DI JAKARTA
}

\author{
Heri Murtiyoko \\ Universitas Pamulang, Tangerang Selatan, Banten, Indonesia \\ dosen01036@unpam.ac.id
}

Manuskrip: Okt-2020; Ditinjau: Nov-2020; Diterima: Nov-2020; Online: Jan-2021; Diterbitkan: Jan-2021

\begin{abstract}
ABSTRAK
Penelitian ini bertujuan untuk mengetahui pengaruh penempatan kerja terhadap kinerja karyawan pada PT. Satria Putra Jaya di Jakarta. Metode yang digunakan adalah explanatory research dengan sampel sebanyak 70 responden. Teknik analisis menggunakan analisis statistik dengan pengujian regresi, korelasi, determinasi dan uji hipotesis. Hasil penelitian ini variabel Penempatan Kerja diperoleh nilai rata-rata skor sebesar 3,730 dengan kriteria baik. Variabel kinerja karyawan diperoleh nilai rata-rata skor sebesar 3,779 dengan kriteria baik. Penempatan Kerja berpengaruh positif dan signifikan terhadap kinerja karyawan dengan nilai persamaan regresi $\mathrm{Y}=12,751+0,671 \mathrm{X}$, dan nilai koefisien korelasi 0,780 atau memiliki tingkat hubungan yang kuat dengan nilai determinasi 60,8\%. Uji hipotesis diperoleh signifikansi $0,000<0,05$.
\end{abstract}

Kata Kunci: Penempatan Kerja, Kinerja Karyawan.

\begin{abstract}
This study aims to determine the effect of job placement on employee performance at PT. Satria Putra Jaya in Jakarta. The method used is explanatory research with a sample of 70 respondents. The analysis technique uses statistical analysis with regression testing, correlation, determination and hypothesis testing. The results of this study, the work placement variable obtained an average score of 3.730 with good criteria. Employee performance variables obtained an average score of 3.779 with good criteria. Job placement has a positive and significant effect on employee performance with the regression equation $Y=12.751+$ $0.671 X$, and the correlation coefficient value is 0.780 or has a strong level of relationship with a determination value of 60.8\%. Hypothesis testing obtained a significance of $0.000<0.05$.
\end{abstract}

Keywords: Job Placement, Employee Performance. 


\section{PENDAHULUAN}

\section{A. Latar Belakang Masalah}

Memasuki era globalisasi, kebutuhan mutlak akan sumber daya manusia yang tangguh tidak dapat dipungkiri dalam menghadapi era baru ini, organisasi atau perusahaan akan memenuhi suatu bentuk persaingan yang semakin kompleks dengan variasi, intensitas dan cakupan yang mungkin belum pernah dialami sebelumnya, sehingga organisasi membutuhkan orang-orang yang tangguh, yang sanggup beradaptasi dengan cepat untuk setiap perubahan yang terjadi, yang sanggup bekerja dengan caracara baru melalui kecakapan dan tugas-tugasnya.

Faktor pertimbangan yang tepat dalam penempatan seseorang dalam bidang tugas baik penempatan awal, pemindahan maupun promosi menjadi sangat penting dan menarik untuk dipelajari. Namun demikian dalam praktek, pertimbangan yang cermat dalam penempatan, perpindahan maupun promosi kurang mendapatkan perhatian yang proposional.

Pelaksanaan kinerja karyawan pada PT. Satria Putra Jaya masih belum efektif disinyalir disebabkan oleh penempatan karyawan yang tidak optimal. Permasalahan tersebut disebabkan oleh penurunan kinerja dikarenakan tidak sesuainya penempatan kerja karyawan, terdapat 4 hal yang mempengaruhi kinerja karyawan dalam hal prestasi pekerja, keahlian, perilaku, kepemimpinan. Kinerja adalah hasil kerja secara kualitas dan kuantitas yang dicapai oleh seorang karyawan dalam melaksanakan fungsinya sesuai dengan tangggung jawab yang diberikan kepadanya. Berdasarkan observasi awal peneliti melihat bahwa kinerja karyawan PT. Satria Putra Jaya belum maksimal, hal ini terlihat dari pencapaian kinerja karyawan yang dicapai belum maksimal, Keahlian yang dimiliki karyawan belum dikeluarkan semuanya, Sikap dan Perilaku karyawan yang kurang baik dalam menyelesaikan pekerjaan.

Penempatan karyawan diharapkan dapat memberikan kontribusi yang memadai bagi organisasi disamping merupakan upaya pengembangan kompetensi sumber daya manusia dalam organisasi. Kesesuaian penempatan karyawan dengan bidang tugas sangat berpengaruh terhadap kepuasan kerja dan kinerja karyawan yang bersangkutan. Penempatan seseorang ke posisi pekerjaan yang tepat, kesesuaian orang dan pekerjaan berarti mencocokkan pengetahuan, keterampilan, dan kemampuan orang dengan karakteristik pekerjaan (Sedarmayanti:2015).

Berkaitan dengan hal tersebut, seperti data tingkat pendidikan pada PT. Satria Putra Jaya jelas perusahaan membutuhkan suatu penempatan tenaga kerja yang cermat dan tepat agar tetap dapat melaksanakan kegiatannya dengan baik dalam mencapai target kinerja karyawan pada bidang kerjanya.

Berdasarkan uraian diatas, maka sebuah perusahaan apabila melaksanakan penempatan kerja yang sesuai dengan keahlian, maka akan meningkatkan kinerja karyawan.

\section{B. Rumusan Masalah}

1. Bagaimana penempatan kerja pada PT. Satria Putra Jaya di Jakarta ?.

2. Bagaimana kinerja karyawan pada PT. Satria Putra Jaya di Jakarta ?.

3. Adakah pengaruh antara penempatan kerja terhadap kinerja karyawan pada PT. Satria Putra Jaya di Jakarta?.

\section{Tujuan Penelitian}

1. Untuk mengetahui kondisi penempatan kerja pada PT. Satria Putra Jaya di Jakarta.

2. Untuk mengetahui kondisi kinerja karyawan pada PT. Satria Putra Jaya di Jakarta. 
3. Untuk mengetahui pengaruh antara penempatan kerja terhadap kinerja karyawan pada PT. Satria Putra Jaya di Jakarta.

\section{METODE PENELITIAN}

1. Populasi

Populasi dalam penelitian ini berjumlah 70 responden PT. Satria Putra Jaya di Jakarta

2. Sampel

Teknik pengambilan sampling dalam penelitian ini adalah sampel jenuh, dimana semua anggota populasi dijadikan sebagai sampel. Dengan demikian sampel dalam penelitian ini sampel yang digunakan berjumlah 70 responden.

3. Jenis Penelitian

Jenis penelitian yang dipakai adalah asosiatif, dimana tujuannya adalah untuk mengetahui atau mencari keterhubungan antara variabel independen terhadap variabel dependennya

\section{Metode Analisis Data}

Dalam menganalisis data digunakan uji validitas, uji reliabilitas, analisis regresi linier sederhana, analisis koefisien korelasi, analisis koefisien determinasi dan pengujian hipotesis.

\section{HASIL PENELITIAN DAN PEMBAHASAN}

\section{Analisis Deskriptif}

Pada pengujian ini digunakan untuk mengetahui skor minimum dan maksimum skor tertinggi, ratting score dan standar deviasi dari masing-masing variabel. Adapun hasilnya sebagai berikut:

Tabel 1. Hasil Analisis Descriptive Statistics

Descriptive Statistics

\begin{tabular}{lr|r|r|r|r} 
& \multicolumn{5}{c}{ Descriptive Statistics } \\
& N & Minimum & Maximum & Mean & Std. Deviation \\
\hline Penempatan Kerja (X) & 80 & 28 & 44 & 34.00 & 4.016 \\
\hline Kinerja Karyawan (Y) & 80 & 29 & 49 & 38.11 & 4.183 \\
\hline Valid N (listwise) & 80 & & & & \\
\hline
\end{tabular}

Penempatan Kerja diperoleh varians minimum sebesar 29 dan varians maximum 49 dengan ratting score sebesar 3,730 dengan standar deviasi 4,648. Skor ini termasuk pada rentang sakala 3,40-4,19 dengan kriteria baik atau setuju.

Kinerja karyawan diperoleh varians minimum sebesar 29 dan varians maximum 48 dengan ratting score sebesar 3,779 dengan standar deviasi 4,000. Skor ini termasuk pada rentang sakala 3,40 - 4,19 dengan kriteria baik atau setuju.

\section{Analisis Verifikatif.}

Pada analisis ini dimaksudkan untuk mengetahui pengaruh variabel independen terhadap variabel dependen. Adapun hasil pengujian sebagai berikut:

\section{a. Analisis Regresi Linier Sederhana}

Uji regresi ini dimaksudkan untuk mengetahui perubahan variabel dependen jika variabel independen mengalami perubahan. Adapun hasil pengujiannya sebagai berikut: 
Tabel 2. Hasil Pengujian Regresi Linier Sederhana

Coefficients ${ }^{\text {a }}$

Unstandardized

Coefficients

\begin{tabular}{l|r|r|r|r|r} 
Model & B & Std. Error & Beta & & Sig. \\
\hline 1 (Constant) & 12.751 & 2.454 & & 5.195 & .000 \\
\hline Penempatan Kerja (X) & .671 & .065 & .780 & 10.278 & .000 \\
\hline
\end{tabular}

Berdasarkan hasil pengujian pada tabel di atas, diperoleh persamaan regresi Y $=12,751+0,671 \mathrm{X}$. Dari persamaan tersebut dijelaskan sebagai berikut:

1) Konstanta sebesar 12,751 diartikan jika Penempatan Kerja tidak ada, maka telah terdapat nilai kinerja karyawan sebesar 12,751 point.

2) Koefisien regresi Penempatan Kerja sebesar 0,671, angka ini positif artinya setiap ada peningkatan Penempatan Kerja sebesar 0,671 point maka kinerja karyawan juga akan mengalami peningkatan sebesar 0,671 point.

\section{b. Analisis Koefisien Korelasi}

Analisis koefisien korelasi dimaksudkan untuk mengetahui tingkat kekuatan hubungan dari variabel independen terhadap variabel dependen. Adapun hasil pengujian sebagai berikut:

Tabel 3. Hasil Pengujian Koefisien Korelasi Penempatan Kerja Terhadap Kinerja

Karyawan.

Correlations $^{\mathrm{b}}$

\begin{tabular}{|c|c|c|c|}
\hline & & Motivasi (X1) & $\begin{array}{c}\text { Kinerja } \\
\text { Karyawan }(\mathrm{Y})\end{array}$ \\
\hline \multirow[t]{2}{*}{ Penempatan Kerja (X) } & Pearson Correlation & 1 & $.767^{* *}$ \\
\hline & Sig. (2-tailed) & & .000 \\
\hline \multirow[t]{2}{*}{ Kinerja Karyawan $(\mathrm{Y})$} & Pearson Correlation & $.767^{* *}$ & 1 \\
\hline & Sig. (2-tailed) & .000 & \\
\hline
\end{tabular}

Berdasarkan hasil pengujian diperoleh nilai korelasi sebesar 0,780 artinya Penempatan Kerja memiliki hubungan yang kuat terhadap kinerja karyawan.

\section{c. Analisis Koefisien Determinasi}

Analisis koefisien determinasi dimaksudkan untuk mengetahui besarnya persentase pengaruh dari variabel independen terhadap variabel dependen. Adapun hasil pengujian sebagai berikut:

Tabel 4. Hasil Pengujian Koefisien Determinasi Penempatan Kerja Terhadap Kinerja Karyawan.

\begin{tabular}{|c|c|c|c|c|}
\hline \multicolumn{5}{|c|}{ Model Summary } \\
\hline Model & $\mathrm{R}$ & R Square & $\begin{array}{l}\text { Adjusted R } \\
\text { Square }\end{array}$ & $\begin{array}{l}\text { Std. Error of the } \\
\text { Estimate }\end{array}$ \\
\hline 1 & $.780^{\mathrm{a}}$ & .608 & .603 & 2.521 \\
\hline
\end{tabular}

Berdasarkan hasil pengujian diperoleh nilai determinasi sebesar 0,608 artinya Penempatan Kerja memiliki kontribusi pengaruh sebesar 60,8\% terhadap kinerja karyawan, sedangkan sisanya sebesar 39,2\% dipengaruhi oleh faktor lain yang tidak dilakukan penelitian.

\section{d. Uji Hipotesis}

Pengujian hipotesis dengan uji t digunakan untuk mengetahui hipotesis mana yang diterima. Rumusan hipotesis: Terdapat pengaruh yang signifikan antara 
Penempatan Kerja terhadap kinerja karyawan.

Tabel 5. Hasil Uji Hipotesis Penempatan Kerja Terhadap Kinerja Karyawan.

Coefficients $^{\mathbf{a}}$

Unstandardized

Coefficients

\begin{tabular}{|c|c|c|c|c|c|}
\hline \multirow[b]{2}{*}{ Model } & \multicolumn{2}{|c|}{ Coefficients } & \multirow{2}{*}{$\begin{array}{c}\text { Coefficients } \\
\text { Beta }\end{array}$} & \multirow[t]{2}{*}{$\mathrm{t}$} & \multirow[t]{2}{*}{ Sig. } \\
\hline & $\mathrm{B}$ & Std. Error & & & \\
\hline 1 (Constant) & 12.751 & 2.454 & & 5.195 & .000 \\
\hline Penempatan Kerja (X) & .671 & .065 & .780 & 10.278 & .000 \\
\hline
\end{tabular}

Berdasarkan hasil pengujian pada tabel di atas, diperoleh nilai t hitung $>\mathrm{t}$ tabel atau $(10,278>1,995)$, dengan demikian hipotesis yang diajukan bahwa terdapat pengaruh yang signifikan atara Penempatan Kerja terhadap kinerja karyawan diterima.

\section{PEMBAHASAN HASIL PENELITIAN}

\section{Kondisi Jawaban Responden Variabel Penempatan Kerja}

Berdasarkan jawaban responden, variabel Penempatan Kerja diperoleh ratting score sebesar 3,730 berada di rentang skala 3,40-4,19 dengan kriteria baik atau setuju.

\section{Kondisi Jawaban Responden Variabel Kinerja Karyawan}

Berdasarkan jawaban responden, variabel kinerja karyawan diperoleh ratting score sebesar 3,779 berada di rentang skala 3,40 - 4,19 dengan kriteria baik atau setuju.

\section{Pengaruh Penempatan Kerja Terhadap Kinerja Karyawan}

Penempatan Kerja berpengaruh signifikan terhadap kinerja karyawan dengan persamaan regresi $\mathrm{Y}=12,751+0,671 \mathrm{X}$, nilai korelasi sebesar 0,780 atau memiliki hubungan yang kuat dengan kontribusi pengaruh sebesar $60,8 \%$. Pengujian hipotesis diperoleh nilai $t$ hitung $>\mathrm{t}$ tabel atau $(10,278>1,995)$. Dengan demikian hipotesis yang diajukan bahwa terdapat berpengaruh signifikan antara Penempatan Kerja terhadap kinerja karyawan diterima.

\section{V.PENUTUP}

\section{Kesimpulan}

a. Variabel Penempatan Kerja diperoleh ratting score sebesar 3,730 berada di rentang skala 3,40 - 4,19 dengan kriteria baik atau setuju.

b. Variabel kinerja karyawan diperoleh ratting score sebesar 3,779 berada di rentang skala 3,40-4,19 dengan kriteria baik atau setuju.

c. Penempatan Kerja berpengaruh signifikan terhadap kinerja karyawan dengan persamaan regresi $\mathrm{Y}=12,751+0,671 \mathrm{X}$, nilai korelasi sebesar 0,780 atau kuat dan kontribusi pengaruh sebesar $60,8 \%$ sedangkan sisanya sebesar $39,2 \%$ dipengaruhi faktor lain. Uji hipotesis diperoleh nilai $t$ hitung $>t$ tabel atau $(10,278>1,995)$.

\section{Saran}

a. Indikator kemampuan, untuk saat ini masih ada kesalahan kerja yang dilakukan dalam setiap pekerjaan yang diberikan terlihat dari hasil kuesioner yang disebar menghasilkan persentase yang cukup untuk kesalahan dalam setiap pekerjaan. Kedepannya agar dapat ditingkatkan lagi kemampuan dalam mengerjakan setiap pekerjaan yang diberikan.

b. Indikator kinerja karyawan, untuk meningkatkan kinerja kedepan selain memperhatikan sikap dan kehandalan karyawan agar dapat tercipta kinerja yang 
lebih baik, perusahaan juga harus memperhatikan pemberian kompensasi, lingkungan pekerjaan, pemberian insentif, gaya kepemimpinan dan sebagainya.

\section{DAFTAR PUSTAKA}

Arikunto, Suharismi. 2010. Prosedur Penelitian Suatu Pendekatan Praktik. Jakarta. PT. Rineka Cipta Edisi Revisi cetakan keempat belas.

Bangun, Wilson. 2012. Manajemen Sumber Daya Manusia. Jakarta : PT. Gelora Aksara Pratama.

Effendy, A. A., Sunarsi, D., Kristianti, L. S., Irawati, L., \& Wahyitno, W. (2020). Effect Of Giving Reward and Motivation to Employee Productivity In PT. Sinar Kencana Jaya In Surabaya. HUMANIS (Humanities, Management and Science Proceedings), $1(1)$.

Fahmi, Irham. 2013. Perilaku Organisasi. Bandung : CV. Alfabeta. Cetakan Pertama.

Hasibuan, Malayu S.P. 2012. Manajemen Sumber Daya Manusia. Jakarta : Bumi Aksara.

Hidayat, D., Prabowo, B., \& Anwar, S. (2020). Organizational Leadership and Conflict in Human Resource Management Review. Solid State Technology, 63(6), 1372-1381.

Irianto, Jusuf.2011. Manajemen Personalia \& Sumber Daya Manuisa. Yogyakarta. BPFE. Edisi Kedua, Cetakan Ketujuh Belas.

Mangkunegara, Anwar Prabu A.A. 2013. Manajemen Sumber Daya Manusia Perusahaan. Bandung : PT. Rermaja Rosdakarya. Cetakan kedua belas.

Mangkuprawira, Sjafri. Tb. 2011. Manajemen Sumber Daya Manusia Strategik. Jakarta. Ghalia Indonesia. Cetakan Pertama (Edisi Kedua) Oktober.

Marwansyah, 2012. "Manajemen Sumber Daya Manusia" Edisi Kedua. CV. Alfabeta. Bandung

Mathis, L. Robert dan John H. Jackson.. 2009. Manajemen Sumber Daya Manusia. Jakarta. Salemba Empat.

Nawawi, Hadari. 2008. Manajemen Sumber Daya Manusia. Yogyakarta : Gadjah Mada University Press. Cetakan Sepuluh.

Sedarmayanti. 2009. Sumber Daya Manusia dan Produktivitas Kerja. Bandung : CV. Mandar Maju.

Simamora, Henry. 2014. Manajemen Sumber Daya Manusia. Yogyakarta : STIE YKPN

Sugiyono.2008. Metode Penelitian Bisnis. Bandung: CV. Alfabeta. Cetakan ke dua belas.

Sunarsi, D. (2017). Pengaruh Kepemimpinan Dan Budaya Organisasi terhadap Kinerja Karyawan Pada Cabang Pembantu Bank DKI Pondok Labu-Jakarta Selatan. JENIUS, 1(2), 21.

Sunarsi, D., Winata, H., Gunartin, G., \& Paeno, P. (2020). Analisis Gaya Kepemimpinan Kepala Desa Dalam Pengembangan Desa Cidokom Gunung Sindur Kabupaten Bogor. Jurnal Ekonomi Efektif, 2(3).

Sutrisno, Edy. 2009. Manajemen Sumber Daya Manusia. Jakarta. Kencana. Edisi pertama. Cetakan pertama.

Sutrisno, S., \& Sunarsi, D. (2019). The Effect of Work Motivation and Discipline on Employee Productivity at PT. Anugerah Agung in Jakarta. Jurnal Ad'ministrare, 6(2), 187-196.

Wibowo. 2008. Manajemen Kinerja. Jakarta : PT. Raja Grafindo Persada. Edisi keempat. Widodo, Suparno Eko. 2015. Manajemen Pengembangan Sumber Daya Manusia. Yogyakarta : Pustaka Pelajar. Cetakan kedua. 